\title{
Analysis of the Residual Stress in ARMOX 500T Armour Steel and Numerical Study of the Resultant Ballistic Performance
}

\author{
Michael Saleh ${ }^{1,5, a^{*}}$, Vladimir Luzin ${ }^{2, b}$, Muhammad M. Kariem ${ }^{3, \mathrm{c}}$, Dong Ruan ${ }^{4,5, \mathrm{~d}}$ \\ ${ }^{1}$ Nuclear Fuel Cycle, ANSTO. Locked Bag 2001, Kirrawee DC, NSW, 2232. Australia \\ ${ }^{2}$ Australian Centre for Nuclear Scattering, ANSTO, Locked Bag 2001, Kirrawee DC, NSW, \\ 2232. Australia \\ ${ }^{3}$ Faculty of Mechanical and Aerospace Engineering, Bandung Institute of Technology, Ganesha \\ 10 Street, Bandung, West Java, 40132, Indonesia \\ ${ }^{4}$ Faculty of Engineering and Industrial Sciences, Swinburne University of Technology, John \\ Street, Hawthorn, VIC 3122, Australia \\ ${ }^{5}$ DMTC, Level 2, 24 Wakefield St. Hawthorn. VIC 3122. Australia \\ a mis@ansto.gov.au, ${ }^{b}$ vll@ansto.gov.au, ${ }^{c}$ kariem.itb@gmail.com, ${ }^{d}$ druan@swin.edu.au
}

\section{Keywords: Residual Stress, ARMOX, Ballistic, FEA, Johnson-Cook}

\begin{abstract}
Armour steels and their response to ballistic and blast threats have been dutifully studied in light of increased conflict and advances in protection levels. The strength of these quenched and tempered martensitic steels is a result of micro alloying, $\mathrm{Ni} \mathrm{Cr}$, and $\mathrm{Mn}$, a combination of hot and cold rolling of the steel and proprietary heat treatments. The resultant hardness and toughness are pronounced and are reflected in the ballistic performance of the steel, although the role of the residual stress (RS) has not been unambiguously confirmed. To elucidate the effects of the RS on ballistic properties a two-step study was performed. Firstly, stress measurements were carried out on ARMOX 500T on the RS diffractometer KOWARI at ANSTO on a $8.3 \mathrm{~mm}$ thick plate. Stress components in rolling and transverse directions were calculated. Using the experimentally measured stress profiles as an input, numerical analysis was carried out on the ballistic response of the plate to the $7.62 \mathrm{~mm}$ APM2 round. Since numerical modelling inherently require the evaluation of material properties at elevated strain rates, to gauge the impact driven stress-strain response, the material's responses were derived using experiments utilising quasi-static testing and instrumented high strain rate experiments using the Split Hopkinson Pressure Bar (SHPB) at Swinburne University, Australia. These experimentally determined high strain rate data were incorporated into the Johnson-Cook (J-C) computational models for the flow stress along with literature sourced parameters for the failure model of the plate. Analysis of the two starting conditions, with and without residual stress, allows the authors to draw some conclusion about the role of the residual stress on the ballistic performance of ARMOX 500T armour steel.
\end{abstract}

\section{Introduction}

The evaluation of ballistic impact performance is often done through experimental testing. Analogously FEA (Finite Element Analysis) can be used as a predictive tool for the optimisation and validation of armour designs and to investigate the likely failure mechanism. RS are known to play a significant role in many material failure processes (e.g. fatigue, fracture, and stress corrosion cracking) [2], which are not characterised by high strain rate deformation of dynamic failure as in the case of ballistic impact. Based on a literature review of hot rolled high strength steels, the role of RS on their dynamic failures is yet to be fully elucidated, studies of HSLA-100 [3] under impact exhibited a pronounced stress field, for the as-received material, in the through plate thickness, analogous to the current study although with a dissimilar tensile stress magnitude. Another example 
can be found for SS 316 weldments [4] under impact. In a previous study the design of multi-layered armour systems has been found to be beneficial [5] in reducing the aerial density with a commensurate increase in performance when compared to homogenous rolled armour alone, RS was not a part of that study. Since all armour materials (plates) have RS of varying magnitude as a result of the manufacturing routes, a study of the role of the RS is desirable. To better clarify the ballistic behaviour and performance of armour steels the current study looks to measure the RS in $8.3 \mathrm{~mm}$ thick ARMOX 500T plate, quantify high strain rate material behaviour through SHPB testing and combine these into numerical FEA modelling to evaluate ballistic performance in several regimes.

Apart from the ballistic performance, the knowledge of the RS in armour plates is important for a number of other reasons. Commonly the compressive residual stresses at the surface can improve the resistance to crack initiation when a tensile load is applied. This may also improves fatigue strength and resistance to stress-corrosion cracking for vehicle mounted amour steels. Conversely, tensile RS at the surface are undesirable as they increase the overall stress level. It is widely accepted that these can lead to stress-corrosion cracking and fatigue failure by reducing the fatigue life and strength of the part.

\section{Microstructure and material properties}

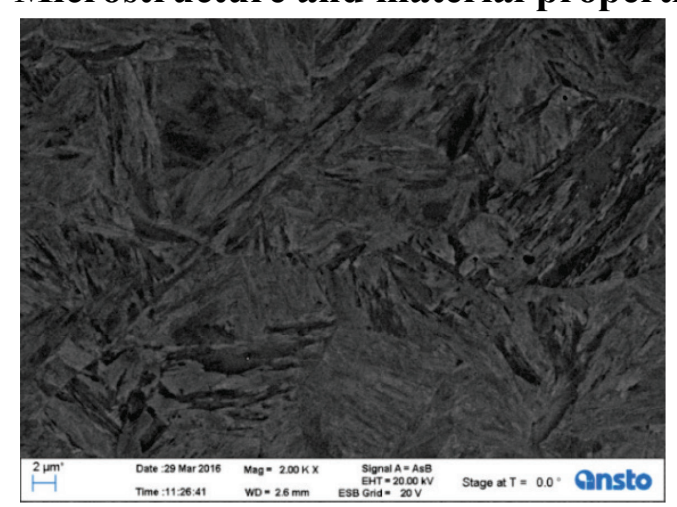

Fig 1. SEM image of microstructure of as received ARMOX $500 T(2000 \times)$.
ARMOX 500T belongs to a class of quenched and tempered high strength steel which are predominately used in amour applications [6-9]. The material is characterised by a high chemical purity, as shown in Table 1, with high $\mathrm{Mn}$ and $\mathrm{Ni}$, to stabilise the steel in quenching, reduce distortion of the plate and to increase the hardenability and hardness depth. Typically the production of these armour steels involves hot rolling at a homologous temperature of $\mathrm{T}^{*}=0.8$. The cut plates are then evenly quenched from a temperature of $\mathrm{T}^{*}=0.65$ to form a largely martensitic

microstructure. Low carbon steels such armour steel have small amounts of retained austenite but these steels are often tempered at $\mathrm{T}^{*}=0.1-0.3$ to increase ductility.

Secondary processes such as welding or cutting of ARMOX 500T are done below the tempering temperature of $200^{\circ}, \mathrm{T}^{*}=0.1$ as the steels strength is negatively impacted. These low tempering temperature allow for the decomposition of the small amount of retained austenite to martensite albeit with a smaller reduction in the internal stresses when compared with higher tempering temperatures [10]. The resultant fine grained lathe martensite structure can be seen in Fig 1.

\begin{tabular}{|l|l|l|l|l|l|l|l|l|}
\hline C \% & $\begin{array}{l}\mathrm{Si} \\
\%\end{array}$ & $\mathrm{Mn} \%$ & $\mathrm{P} \%$ & $\mathrm{~S} \%$ & $\begin{array}{l}\mathrm{Cr} \\
\%\end{array}$ & $\begin{array}{l}\mathrm{Ni} \\
\%\end{array}$ & Mo \% & $\mathrm{B} \%$ \\
\hline 0.32 & 0.4 & 1.2 & 0.015 & 0.010 & 1.0 & 1.81 & 0.7 & 0.005 \\
\hline \multicolumn{8}{c|}{ Table 1 Typical composition of ARMOX 500T. }
\end{tabular}

\section{High-strain rate testing}

One method to quantify the high strain rate performance, which is readily used is armour testing, is the SHPB $[11,12]$. The test involves a striker bar being fired at the incident bar with a pre-specified velocity. This induces stress waves, which propagate through the incident bar. Upon reaching the interface with the specimen the stress pulse is partially reflected back through the incident bar, whilst a portion of the pulse is transmitted through the specimen and into the transmitter bar. By placing strain gauges on both the incident bar and the transmitter bar the strain histories can be evaluated. The stress and strain can be evaluated through the Kolsky relation [13]. 


\section{Neutron diffraction experiment}

Neutron RS measurements in the $8.3 \mathrm{~mm}$ thick ARMOX 500T plate were performed on the KOWARI neutron diffractometer at the OPAL research reactor at ANSTO [14]. The Fe(211) reflection was used at $90^{\circ}$-geometry employing a neutron wavelength of $\lambda=1.67 \AA$. Three principal directions, rolling (RD), transverse (TD) and normal (ND), were measured scanning through thickness in $0.5 \mathrm{~mm}$ steps with a nominal gauge volume of size of $0.8 \times 0.8 \times 20 \mathrm{~mm}^{3}$ and resulting in overall 17 point strain profiles. The high flux of KOWARI, optimised for this wavelength, yielded average strain accuracy better than $50 \mu$ strain (or $\sim 10 \mathrm{MPa}$ in stress scale after calculations and error propagation) in $\sim 7$ minutes of beam time. Of the three strain measurements two stress components were recalculated for RD and TD Fig3. (a), as well as $\mathrm{d}_{0}$ values Fig.3 (c), assuming the zero plane stress condition. In the authors' opinion this is the most valid approach for stress calculation in the current case. The applicability of the plane-stress condition in thin plates can be based on theoretical consideration using the equation of equilibrium for the normal component, $\partial \sigma_{33} / \partial x_{3}=$ $-\left(\partial \sigma_{13} / \partial x_{1}+\partial \sigma_{23} / \partial x_{2}\right)$, where $x_{3}$ is the through-thickness dimension and $x_{1}$ and $x_{2}$ are the inplane coordinates. In case of large uniform plate, with no gradient in $x_{1}$ and $x_{2}$ dimensions, there is also no gradient of the $\sigma_{33}$ in the through-thickness direction and since $\sigma_{33}=0$ exactly on the both surfaces, this holds true through the whole thickness.

\section{Constitutive modelling}

The experimentally derived stress strain curves are fit to the three parameter $\mathrm{J}-\mathrm{C}$ constitutive model [15] and is used to compute the flow stress of materials under high strain:

$$
\sigma_{e q}=\left[A+B \varepsilon^{n}\right]\left[1+C \ln \dot{\varepsilon}^{*}\right]\left[1-\left(T^{*}\right)\right],
$$

where $\sigma_{e q}$ is the flow stress, $\varepsilon$ is the effective plastic strain, $\dot{\varepsilon}^{*}=\dot{\varepsilon} / \dot{\varepsilon}_{0}$ is the dimensionless plastic strain rate, $T^{*}=\frac{T-T_{0}}{T_{\text {melt }}-T_{0}}$ is the homologous temperature and $\mathrm{A}, \mathrm{B}, \mathrm{n}, \mathrm{C}$ and $\mathrm{m}$ are material constants. This phenomenological model accounts for (i) the increase in yield stress due to strain hardening through dislocation pile up (ii) the increase in yield and tensile strength with increased strain rate and (iii) the thermal softening of the material due to thermal-plastic instability. The temperature increase is assumed adiabatic. Johnson and Cook [16] also developed a fracture model for ductile materials focusing on the stress tri-axiality sensitivity. The failure strain is computed from a multiplicative relation that expresses the stress tri-axiality, $\sigma^{*}=\frac{P}{\sigma_{e q}}$, where $\mathrm{P}$ is the hydrostatic stress, strain rate dependence and the homologous temperature, where $\mathrm{D}_{1}, \mathrm{D}_{2}, \mathrm{D}_{3}, \mathrm{D}_{4}, \mathrm{D}_{5}$ are the J-C Fracture strain model constants:

$$
\varepsilon_{f}=\left(D_{1}+D_{2} \exp \left(D_{3} \sigma^{*}\right)\right)\left(1+D_{4} \ln \left(\dot{\varepsilon}^{*}\right)\right)\left(1+D_{5} T^{*}\right) .
$$

The $7.62 \mathrm{~mm}$ projectile, Fig. 2, is similarly modelled using a modified version of the J-C model as outlined in [8]. A breakdown of the derivation and the applicability of the newly derived high strain data will be analysed in a future publication. Preliminary strength model constants for ARMOX 500T are listed in Table 2. Damage model contstants are reproduced from [17].

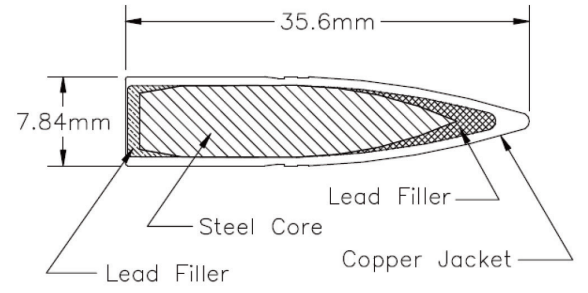

Fig. 2 Schematic of $7.62 \mathrm{~mm}$ APM2 [1].

\begin{tabular}{|l|c|c|c|c|}
\hline$A[G P a]$ & \multicolumn{1}{|c|}{$B[G P$} & $n$ & $C$ & $m$ \\
\hline 0.385 & 1.405 & $\begin{array}{c}0.0 \\
263\end{array}$ & $\begin{array}{c}0.0 \\
087\end{array}$ & $\begin{array}{c}1 . \\
044\end{array}$ \\
\hline$D_{1}$ & $D_{2}$ & $D_{3}$ & $D_{4}$ & $D_{5}$ \\
\hline 0.068 & 5.328 & - & 0 & 0 \\
\hline
\end{tabular}

Table $2 \mathrm{~J}$-C flow stress and failure model constants for ARMOX 500T. 


\section{Results of residual stress}

The macro-stress profile in the through thickness of the steel plate is shown in Fig. 3 (a), and exhibits large oscillatory behaviour as a result of the production route. It characterised by large compressive stresses, $-200 \mathrm{MPa}$, present at the surface, tensile stress zones $\sim 1 \mathrm{~mm}$ below the surfaces, $\sim 120 \mathrm{MPa}$, and a moderately compressive zone in the center, $-100 \mathrm{MPa}$. Despite a more pronounced stress in the rolling direction (RD), the similarities of the two profiles, rolling direction and transverse direction (TD), indicate cross rolling was a most likely manufacturing route.

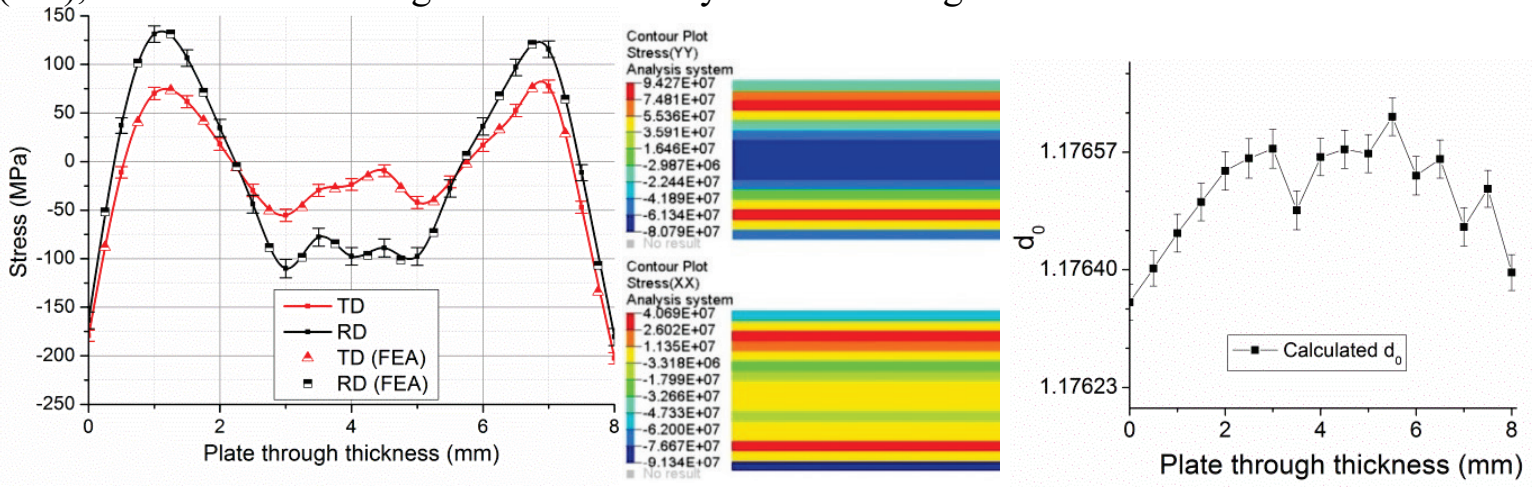

Fig. 3 (a) Residual stress measured using neutron and mapped to FE model (b) contours of the stresses after dynamic relaxation step (c) $d_{0}$ value profile evaluated for the zero stress condition in the through thickness approach.

\section{Results for modelling simulation}

Utilising a numerical routine the resultant stresses shown in Fig. 3 (a) were mapped in the plate's through thickness for the RD stress, $\sigma_{y y}$ and the TD stress, $\sigma_{x x}$ using MATLAB, the stresses were initialised at the integration points using a dynamic relaxation step. The FEA model is built using 3D half symmetry with 500,000 single-point integrated solid elements in LS-DYNA, with a plate through thickness element size of $0.5 \mathrm{~mm}$. Shown in Fig. 3 (b) are the results of the precursor dynamic relaxation simulation in which sample equilibrium is achieved through nodal displacement based on the user defined initial stress. Note that some discrepancies are apparent between these dynamic relaxation stresses and those of the experimental measurements. Greater discretisation of the through thickness mesh would alleviate this issue and will be tackled in future studies.

The numerical LS-DYNA simulation of bullet collision with stressed and stress-free armour plate was performed for four bullet velocities of 450,600, 750 and $900 \mathrm{~m} / \mathrm{s}$ and with $0^{\circ}$ of obliquity. These present velocities above and below the steel's $\mathrm{V}_{50}$ limits [18].
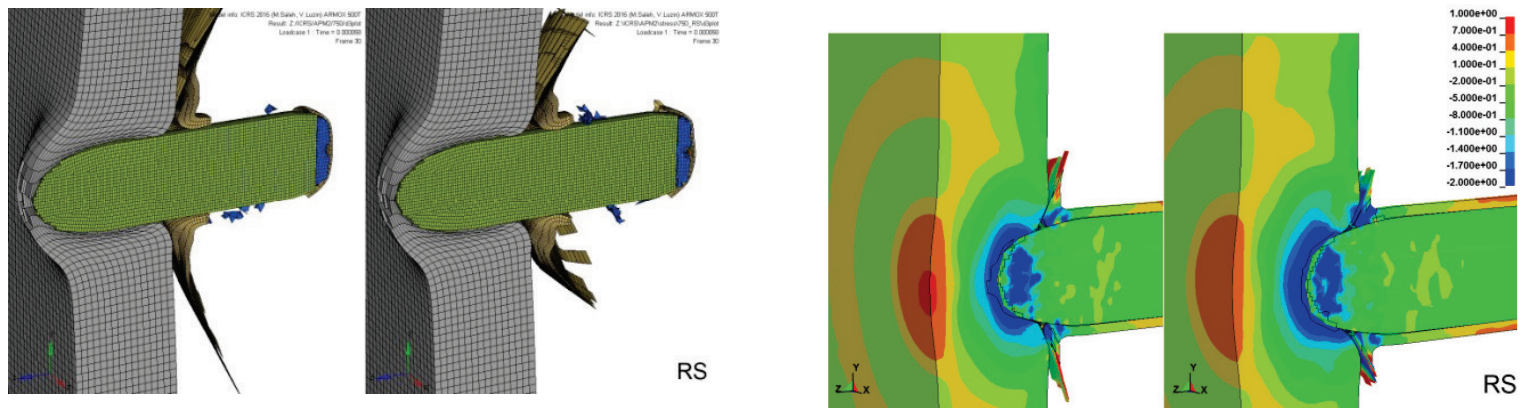

Fig. 4 (a) Deformation of ARMOX $500 T$ for $750 \mathrm{~m} / \mathrm{s}$ APM2 velocity (b) contours of stress triaxiality.

The model results demonstrates the classical ductile hole growth failure mode, whereby the projectile penetrates into the plate by pushing the target material aside, Fig.4(a). There is a small amount of localised bulging with a largely straight penetration channel and no bullet tumbling. The penetration process at $\mathrm{t}=32 \mu \mathrm{s}$ shows the brass jacket stripped from bullet for the higher velocities. 
The lead filler atop the steel core is largely eroded due to adiabatic heating and to a lesser extent the plastic work, the lead filler to the rear of the bullet is damaged by the collapsing brass jacket. This damage is induced by the complex contact which creates disparities in the bullet component's velocities. Some bullet tip erosion is apparent but no pronounced shape variations are shown between the steel with and without RS. The von Mises stress, Fig.5, in the bullets impacting at higher velocities is more apparent and more distributed for the RS plates. We observed a reduction of the residual velocity of the bullet after perforation, at an incident velocity of $900 \mathrm{~m} / \mathrm{s}$, from $453 \mathrm{~m} / \mathrm{s}$ to 444 $\mathrm{m} / \mathrm{s}$ for the RS plate.

For all the scenarios analysed the authors observed a reduction in the back face stress for the RS plates with a correspondingly small reduction in the back face deformation at velocities of $450 \mathrm{~m} / \mathrm{s}$ and $650 \mathrm{~m} / \mathrm{s}$, Fig.6. At higher velocities, $750 \mathrm{~m} / \mathrm{s}$ there is greater propensity for the plate without RS to fail, in penetration, on the back face as seen in Fig 4(a). This stems from the increase in stress triaxiality in the plates without RS, as the large compressive surface stresses in the RS plates improve the ballistic performance by reducing the magnitude of the material with positive tri-axiality, Fig.4(b) while the internal compressive stresses increase the volume of material with negative tri-axiality, also a mitigating mechanism to failure.

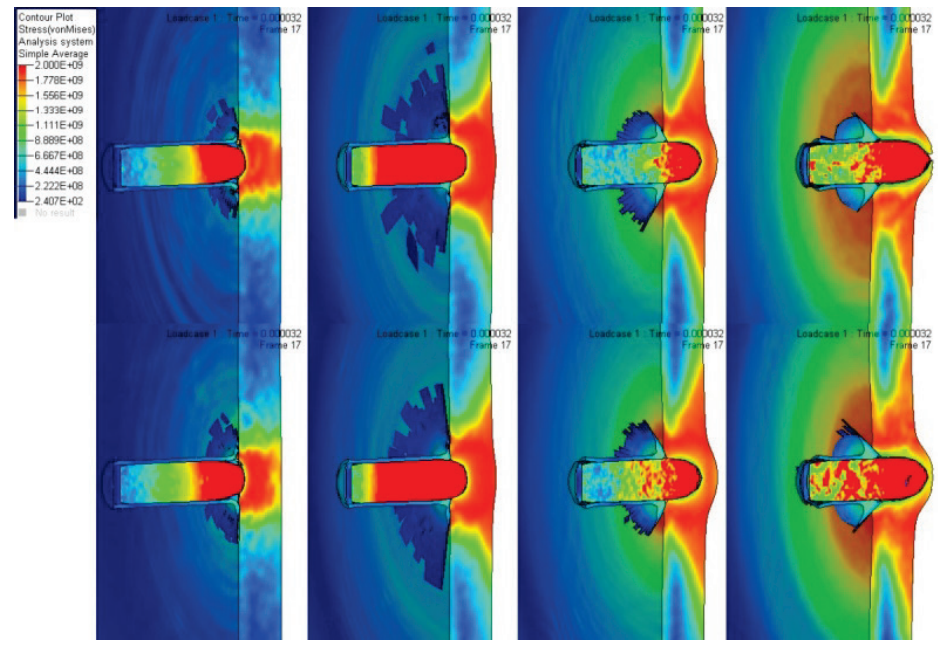

Fig5 von Mises stress for $L-R$ 450,600,750,900 m/s at $t=32 \mu \mathrm{s}$. The bottom 4 results are the models initialised with $R S$.

material ahead of the bullet with negative tri-axiality. There is a small reduction in the residual velocity of the penetrating projectile for RS plates at higher velocities, above $\mathrm{V}_{50}$. The reduction could become more pronounced where multiple sandwiched plated are used and were the cumulative RS effect may not be a simple additive relationship.

\section{Acknowledgement}

D. Shanmugam and R. Smith from THALES for the supply of the ARMOX 500T plate.

\section{References}

1.Showalte, D.D., et al., Ballistic Testing of SSAB Ultra-HighHardness Steel for Armor Applications, 2008, Army Research Laboratory.

2.Noyan, I.C. and J.B. Cohen, Residual Stress Measurement by Diffraction and Interpretation. 1987, New York: Springer Science+Business Media.

\section{Conclusion} 500T has been characterised using neutron diffraction techniques with pronounced compressive and tensile stresses inherited from the production route. Stress mapping of the RS was used to model the ballistic performance of the plate against $7.62 \mathrm{~mm}$ APM coupled with newly parametrised data for $\mathrm{J}-\mathrm{C}$ flow stress model. RS has a small beneficial effect in reducing back face deformation in lower velocity projectile impact, below the ballistic limit. This is through a reduction in the positive triface and an increase in the volume of

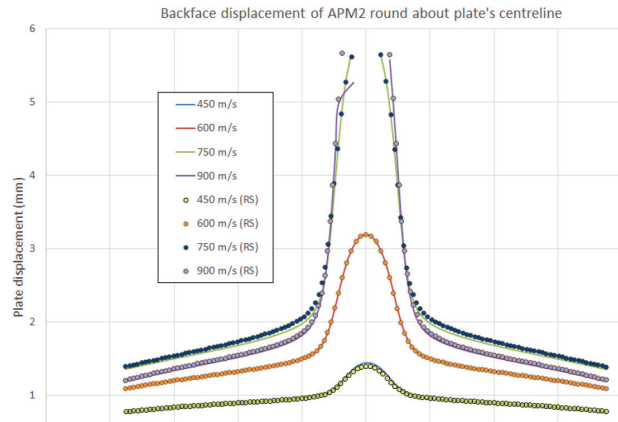

Fig. 6 Back face displacement for the ARMOX $500 T$.
Residual stress for hot rolled ARMOX axiality experienced by the plate's back 
3.Prime, M.B. and R.L. Martineau, Mapping Residual Stresses after Foreign Object Damage Using the Contour Method. Materials Science Forum, 2002. 404-407: p. 521-526.

4.Flores-Johnson, E.A., et al., Numerical analysis of the effect of weld-induced residual stress and plastic damage on the ballistic performance of welded steel plate. Computational Materials Science, 2012. 58: p. 131-139.

5.Flores-Johnson, E.A., M. Saleh, and L. Edwards, Ballistic performance of multi-layered metallic plates impacted by a 7.62-mm APM2 projectile. International Journal of Impact Engineering, 2011. 38(12): p. 1022-1032.

6.Jena, P.K., P. Senthil P, and S.K. K, Effect of tempering time on the ballistic performance of a high strength armour steel. Journal of Applied Research and Technology, 2016. 14(1): p. 47-53.

7.Ponguru Senthil, P., et al., Effect of heat treatment on ballistic performance of an armour steel against long rod projectile. International Journal of Impact Engineering, 2015. 80: p. 13-23.

8.Børvik, T., S. Dey, and A.H. Clausen, Perforation resistance of five different high-strength steel plates subjected to small-arms projectiles. International Journal of Impact Engineering, 2009. 36(7): p. 948-964.

9.Maweja, K. and W. Stumpf, The design of advanced performance high strength low-carbon martensitic armour steels: Microstructural considerations. Materials Science and Engineering: A, 2008. 480(1-2): p. 160-166.

10.Bawa, H.S., Manufacturing Processes - Ii. 2004: McGraw-Hill Education (India) Pvt Limited.

11.Lee, W.-S. and G.-W. Yeh, The plastic deformation behaviour of AISI 4340 alloy steel subjected to high temperature and high strain rate loading conditions. Journal of Materials Processing Technology, 1997. 71(2): p. 224-234.

12.Børvik, T., et al., Strength and ductility of Weldox $460 \mathrm{E}$ steel at high strain rates, elevated temperatures and various stress triaxialities. Engineering Fracture Mechanics, 2005. 72(7): p. 1071-1087.

13.Kaiser, M.A., Advancements in the Split Hopkinson Bar Test, 1998, Virginia Polytechnic Institute and State University.

14.Kirstein, O., V. Luzin, and U. Garbe, The Strain-Scanning Diffractometer Kowari. Neutron News, 2009. 20(4): p. 34-36.

15.Johnson, G.R. and W.H. Cook. A constitutive model and data for metals subjected to large strains, high strain rates and high temperatures. in Proc. 7th Int. Symp. on Ballistics. 1983. The Netherlands.

16.Johnson, G.R. and W.H. Cook, Fracture characteristics of three metals subjected to various strains, strain rates, temperatures and pressures. Engineering Fracture Mechanics, 1985. 21(1): p. 31-48.

17.WIŚNIEWSKI, A. and P. ŻOCHOWSKI, Building and Validation of the Johnson-Cook Constitutive Model of Nano-Composite NANOS-BA ${ }^{\circledR}$ Steel for Armour Applications in 9th International Armament Conference on Scientific Aspects of Armament and Safety Technology2012: Poland.

18.DoD, Department of Defence Test method standard: V50 ballistic test for armor, 1997: USA. 